\title{
Tarihin Tekerini Geriye Döndürmek: Moda Tasarımında Geleneği Yorumlama Sorunsalı
}

Yüksel ŞAHIN*

Özet

Bu makalede, Endüstri Devrimi'nden sonra gelişen yeni giyim-kuşam alışkanlıklarından duyulan kaygıyla Osmanlı aydınları tarafından tartışılan 'bir milli moda yaratmalıyız' önermesi ışığında, günümüzde bir kısım akademisyen ve tasarımcı tarafından önerilen; 'moda tasarımında geleneği yorumlama' savı ve 'geleneksel olanı kavrayış', eleştirel biç̧imde ele alınmıştır. Konu, Osmanlıdan günümüze kadar yapılan gelenekçi önermeler çerçevesinde, Batı’nın Endüstri Devrimi sürecinde geliştirdiği bilim, kültür, sanat ve tasarım alanındaki yaklaşımlarıyla irdelenmiş̧tir.

Anahtar Sözcükler: Glasgow Sanat Okulu, Arts \& Crafts, Estetik Akım, Endüstri Devrimi.

\section{Reversing the Wheel of History: The Problematic of Interpreting the Tradition in Fashion Design}

\section{Abstract}

In this paper, the suggestion of the Ottoman entelectualists 'we should create a national fashion' occured with the apprehension for new clothing habits gained after the Industrial Revolution is disscussed. The suggestions of 'interpreting the tradition in fashion design' and the comprehension of what is 'traditional', which are proposed by some academics and designers, are evaluated with a critical approach. The subject is examined within the frame of traditionalist suggestions offered from the time of the Ottomans till today, with the conceptions of the Western science, culture, art and design developed through the period of the Industrial Revolution.

Keywords: Glasgow Art School, Arts \& Crafts, Aesthetic Movement, Industrial Revolution. 


\section{Giriş}

İngiltere'de, tekstil üretimi üzerinden gelişim gösteren Endüstri Devrimi, bilim, sanat ve kültür alanındaki Batılı düşünürleri, bilim insanlarını ve sanatçıları, makine üretiminin doğuracağı sonuçlardan dolayı kaygılandırmış ve harekete geçirmiştir. Arts \& Crafts hareketi, bu kaygıların neticesinde ortaya çıkmıştır.

Endüstri Devrimi'nin hemen öncesinde geleneksel yaşam biçimini sürdüren Batılı toplumların modernleşme sürecinde zengin etnografyalarından yararlanmaları, Arts \& Crafts Hareketi ve 1890'da kurulan 'Aesthetic Movement' (Estetik Akım) ile gerçekleşmiştir. Bu makalenin temel konusu olan moda tasarımı alanı, yukarıda bahsedilen akımlarla eş zamanlı gelişen, kadınların kimlik mücadelesinde (kadınların kamusal alanda görünürlük ve varlık kazanmalarında) faydacı bir alan olarak belirmiştir.

Bu bakımdan, Arts \& Crafts hareketinin başarılı olan sonuçları önem taşımaktadır. Bilindiği üzere, Arts \& Crafts Hareketi'nin iki önemli sonucundan birisi yoğun kadın işsizliğine çare olması, diğeri ise sanatta egemen ataerkil Viktoryan ideolojinin çökmesidir ${ }^{1}$ (Callen, 1985: 1-6). Arts \& Crafts Hareketi'ni de etkileyen Estetik Akım, Viktoryan Dönemi reddederek modaya yön vermiş, rahat ve insan anatomisine uyumlu tasarımlar önermiştir (Stankiewicz, 1992: 165-173). Bu tasarımlar, baskı altında olan kadınların giysi tasarımları üzerinden gelişmiş ve özellikle kadınların bedenlerini rahat kullanmalarına olanak veren kesimler içermiştir.

Kadınların kamusal alanda sadece 'görüntü' olarak değil, beceri ve akıl kullanımı bakımından da var olmalarına olanak tanıyan giysi tasarımlarının talep edilmesi, bazı yeni girişimlerin oluşmasına zemin hazırlamıştır. Bu dönemde, yine İngiltere'de kurulan 'Sanatsal ve Sağlıklı Elbise Derneği', moda tasarım alanındaki çalışmaları, araştırmacı ve uygulamacı bir zeminde tartışmaya açmıştır. Modanın giderek zevksizleşmesine karşı, 'SanatsalEstetik- Elbiseler' (wearable art) önerisini geliştiren İngiltere, güncel modanın içinde kadın giyim stilinde ilk sanat hareketinin merkezi olmuştur. Bütün bu gelişmelerin sonucunda 1893-1894'de açılan 'Estetik Elbiseler' sergisi dikkate değer bir geliş̧me olmuştur (Callen, 1985: 1-6). Londra ve Glasgow, bu yeni giyim etkisinin gelişmesine ve yayılmasına etken olan iki şehir olarak öne çıkmıştır.

Glasgow'da kurulan 'Glasgow Sanat Okulu', 'sanatsal elbise' için özellikle aktif bir merkez haline gelmiştir. Makalenin konusu bağlamında, Glasgow Sanat Okulu incelenmeye değerdir. 1845 yılında ilk Devlet Tasarım Okulu olarak kurulan okul, 19. yüzyıl geç döneminin sanat ve mimarlık eğitimini yeni teknolojileri kapsayacak şekilde yeniden tanımlamıştır. Eğitimde yaratıcılık ve araştırmaya önem verilen okulda, Tekstil-Moda Tasarımı eğitimi öncelikli alanlardan birisi olmuştur. Okulun amacı, geleneksel giyim ve tekstil sanatını, geleneksel tekstil üretim tekniklerini, renk, desen, motif ve kompozisyon özellikleri bakımından yeni moda giysilerde buluşturmak, yeni tasarımlar ile önermelerde bulunmaktır. Öyle ki, okulun tüm eğitmenleri kendi tasarımı olan 'sanatsal elbise'leri giyerek bu düşüncelerini paylaşmışlardır (Arthur, 1980: 18-25).

Moda tasarımı, bu süreçten geçerek 20. yüzyıl başında bilinen bütün stiller ve giysi formlarının köklü bir değişime uğramasıyla gelişmiş, dönemin sanat akımlarının ve eğilimlerinin görüldüğü tasarımlarla tarihteki yerini almıştır (Lehnert, 2000: 8). Aynı dönemde, Osmanlı, Avrupa'da olan biten gelişmeleri takip etmek amacıyla Avrupa'ya heyetler göndermiştir. Avrupa'daki gözlemlerini aktaran bir kısım Osmanlı aydını, İstanbul'a döndüklerinde basının da etkisiyle hızla talep gören Avrupa modasının endişesine kapılarak yenileşmenin taklitle değil, ancak kendimize özgü tasarımlarla olabileceğini yazmışlardır (0s, 2002: 142).

Avrupa'daki kaygılarla örtüşen bu anlayışların doğru zamanlı olduğu düşünülmektedir. Konu üzerinde çözüm önerileri geliştiren Osman Hamdi Bey, 1873 yılında Viyana sergisinde yer alan Osmanlı sergisini Marie de Launay ile birlikte gerçekleştirdiklerinde benzer kaygıları taşımışlar ve Osmanlı İmparatorluğu'nda geleneksel zevklerin ve hünerlerin hızla kaybolmasından yakınmışlardır. Osman Hamdi Bey, küçük sanayici ve esnafın korunma yöntemleri üzerinde durarak geleneksel üretim biçimlerinin koru- 
nabileceğini belirtmiştir (Osman Hamdi \& Launay, 1999: Önsöz'den).

Yine dönemin yazarları, çok farklı türde kıyafeti barındıran İstanbul'da, II. Mahmud'tan sonra görülen Avrupalı giysilerin, farklılıkları bir arada tutan hassas dengeyi sağlayamayacağını, 'modern kıyafetler'in iklimin ve kültürün verilerine duyarsız ve modanın boyunduruğu altında olduğunu ifade etmişlerdir. Buna karşın, 'yerel kıyafet'i rahat ve işlevsel bulmuşlar ve romantik tanımıyla 'muhit ve iklim'in ürünü olan yerel karakterin çeşitliliğin göstergesi olduğunu söylemişlerdir (Osman Hamdi \& Launay, 1999: Önsöz’den). Buradan da anlaşıldığı üzere, Osmanlı aydınları gerçekten de 'geleneksel olanla barışık', yeni giyim anlayışının gerçekleşmesini arzu etmişlerdir. Ancak, bu yöndeki araştırmalar, çalışmalar, denemeler ve uygulamalar, İngiltere'de, Hollanda'da, Fransa'da olduğu gibi tasarım eğitimi üzerinden gerçekleşmemiştir. ${ }^{2}$

19. yüzyıl sonunda 'kendi modamızı yaratabilmenin' gerekli koşulunun, yenilenmesi gereken tekstil üretim tesisleri, tasarım eğitimi, antropolojik ve etnografik araştırmalar olduğu düşünülmüştür. Dönemin mevcut tekstil endüstrisinin teknolojik bakımdan geri kalmış olması, tekstil-moda tasarımı eğitimi veren okulların olmaması ve 'tasarımcı' kavramının henüz bilinmemesi gibi nedenlerle tasarım ile ilgili sorunlar, alan dışı meslek insanlarının önerileri ile gerçekleşmiştir.

Yukarıdaki tespitlerin doğruluğu, Batı modalarının sunduğu yeniliklerin, Osmanlı kadınları ve erkekleri tarafından yakından izlenmesinden de anlaşılabilir. Makine üretimi Avrupa kumaşların yeni pazarlarından birisi İstanbul olmuştur. Ayrıca, moda olgusunun dönemin gazete ve dergileriyle tanıtımı başarılı olmuş; özellikle, kadınlar tarafından 'moda' kavramının büyüsü ile yeni moda giysiler beğeni toplamıştır (Şahin, 2006: 191-192). Ancak, bu giysilerin Avrupa'nın ‘modernleşme dönemi'nin giysileri olduğunun ayırdına varıımamıştır. ${ }^{3}$ Batı ile Doğu arasındaki sosyal yaşam farkına karşın, kamusal alanda yer alma arzusundaki Osmanlı kadınları modaya kuvvetli bir ilgi göstermişlerdir. Moda giysilerle olan etkileşim öncelikle geleneksel giysilerde süsleme, aksesuar unsurlarının kullanılmasıyla başlamış, daha sonra giysinin kendisi ile devam etmiştir (Şahin, 2006: 68).

Batılı giysilerin Doğulu zihniyete uygulanması daha çok deneysel olarak gelişmiştir. Yerel giysileri kesip biçen terzilerin deneyimleri ve fikir yürüterek yaptıkları uygulamalarda, Batı ve Doğu arasındaki zihniyet farklılığı açıkça ortaya çıkmış ve geleneksel kesim bilgisindeki terzilerin yeni moda uyarlamaları 'eklektik' biçimde gerçekleşmiştir. ${ }^{4}$ Daha da önemlisi, bu giysileri giyecek sosyal yaşam ve sosyal davranış biçimleri, doğal gelişimini henüz gerçekleştirememiştir (Şahin, 2011: 181).

Batı modalarının etkisindeki 'kentli' eklektik giysiler, Cumhuriyet'in ilanından sonra kurulan müzelerde 'geleneksel giysiler' tanımlaması ile yer almıştır. Kırsal halk kültürünü temsil eden anlam yüklü geleneksel giyim-kuşam öğeleri ise, teknolojinin henüz ulaşamadığı bölgelerde bir süre yaşamış ve başkalaşarak yok olmaya yüz tutmuşlardır.

Her şeye rağmen, günümüzde araştırmacılar ve tasarımcıların veri bakımından şanssız oldukları düşünülmemektedir. Söz gelimi, Osmanlı döneminde hazırlanmış olan kıyafetnameler, Levni Albümü, 1873 yılında Türkiye'de Halk Giysileri, Elbise-i Osmaniyye Albümü ve Oryantalist gezginlerin gravürleri önemli kaynaklar olarak kaydedildiler. Ayrıca Cumhuriyet Dönemi'nde müzelerin hızla kurulması, 5 halk kültürü araştırmaları, koleksiyonlar, ressam ve yazarların Anadolu kültürlerini eserlerinde konu edinmeleri, konu ile ilgili çalışma yapanlar için başvuru kaynakları olarak önerilmektedir.

\section{Tarihin Tekerini Geriye Döndürmek}

Günümüzden yaklaşık yüz elli yıl öncesinde duyulan kaygı ile yapılan tartışmalar ışı̆̆ında 'tasarımın bugünü' değerlendirildiğinde, 'tekstil ve moda tasarımı' alanında bir hayli mesafe kaydedildiği ve yetenekli tasarımcılarımız olduğu ifade edilebilmektedir. Tarihsel süreçte, Osmanlı aydınlarının kaygılarının söz konusu dönem için haklılık taşıdığı söylenebilir. Fakat son otuz yılda, kimi tasarımcı ve akademisyenin, 'gelenekçi' tasarımlarında, gelenek ile moderni birleştirme ve yorumlama amacındaki öneri ve 
iddialarının tarihi süreçle çelişkili yaklaşımlar içerdiği düşünülmektedir.

Bu alandaki yeni önermeler/tasarımlar, kültüre ve geleneğe sahip çıkmanın yanı sıra, ülke ekonomisine katkıda bulunma iddiası ile yapılandırılmaktadır. Çalışmaların içerik ve yaklaşımları; 'yöresel malzeme ve motif- desen vb.'nin moda tasarımı ürünler üzerinde kullanılarak bölge kalkınmasına katkıda bulunmak, kültürü korumak vb.' şeklinde özetlenebilir. Söz konusu önermeler/tasarımlar incelendiğinde, bunların derin araştırmalardan yoksun olduğu izlenimi edinilmektedir.

Yüzeysel yaklaşımların görüldüğü tasarımların, sürekli kendini tekrar eden önermelere yol açtı̆̆ı gözlemlenmekte ve bunun da 'moda tasarımında geleneği yorumlama sorunsalı'na dönüştüğü düşünülmektedir. Bir sarmal gibi, sürekli olarak kısır döngüde kendini tekrarlayan ve ayrıntıda farklılıklar yaratmaya çalışan bu yaklaşımların, bir bakıma 'tarihin tekerini geriye döndürmeği' teklif ettiği düşünülmektedir.

Moda tasarımında gelenekçi yaklaşımları içeren önermeler, zihinde bazı soruların oluşmasına neden olmuştur. Söz gelimi;

Bu tasarımlar, bir sorun tespit ederek, bunu sosyolojik ve antropolojik bir temele oturtma iddiasında olabilirler mi?

Gelenekten beslendiğini ifade eden ve bir tür törensel giysiye dönüşen bu tasarımlar, yalnızca sahneleme veya performatif bir an içinse 'moda' kavramı ile ilişkilendirilebilir mi?

Burada yapılmak istenen törensel bir sunum olabilir mi?

$\mathrm{Bu}$, oryantalistlerin 'etnomaskeleme'sine benzeyen bir yaklaşım olabilir mi? ${ }^{6}$ (Bkz.: Konuk, 2008: 169).

Törensel kurallara göre sunulan bu giysilerde yer alan kültür öğeleri, o giysiyi özgün ve başarılı kılmakta mıdır (aktarılmış biçimler ve şekillerle)?

Bu tasarımların bir temsil hali var mıdır?

Yeni moda tasarımlarında kullanılan gelenekçi yaklaşımlar, yeni bir alışkanlık ${ }^{7}$ yaratma girişimi olabilir mi?
Eğer moda tasarımında geleneksel yaklaşımların yer almasındaki amaç, 'yabancılaşma’ya karşı geç kalınmış bir öneri ya da bir alışkanlık yaratma önerisi değilse, kimliklendirme çalışması olabilir mi?

Moda tasarımında herhangi bir geleneksel öğenin kullanımı, kültürü başkalaştırma, kimliksizleştirme, hatta kültürün kendisine yabancılaştırma etkisinde olabilir mi?

Moda ürünü, yeniliklerle pazarlanabilir nesneye dönüşürken, 'etnosantrik' giysiler kaç sezon peş peşe önerilebilir? Bunların küresel moda pazarında yaşaması mümkün olabilir mi?

Bu sorulara yanıt verebilmek, Endüstri Devrimi sürecinde Batı'nın deneyimleri ve düşünürlerin yaklaşımlarının gözden geçirilmesiyle mümkün olabilir. Endüstri Devrimi, öncesi ve sonrası, felsefeciler, antropologlar, etnologlar, sosyologlar, sanatçllar ve psikanalistlerce 'yabancılaşma', 'alışkanlık', 'temsil değer', 'otobiyografik zaman', 'simgesel dil', 'popüler kültür' vb. kavram ve olgularla tartışılmıştır.

Bu yaklaşımlarla, Endüstri Devrimi'nin, salt bir tarih anlatısı olmaktan çıktığı görülür. Çalışmanın bundan sonraki kısmında, söz konusu tartışmalar çerçevesinden bakılarak günümüzde yapılan önermelerin, bu yaklaşımlardan ne kadar haberdar olabildiği sorgulatılmaya çalışılmıştır.

Tunalıya (2009: 65) göre, 'yabancılaşma' kavramı, Endüstri Devrimi'nin peşi sıra 20. yüzyılda gelişen teknoloji ve endüstriyle beraber toplum yaşamında meydana gelmiştir. Tunalı (2009: 65), daha 18. yüzyılda Jeanlacques Rousseau'nun 'yabancılaşma' kavramını politik bir içerikle ele aldığını ve daha sonraki yüzyılda Hegel ve Marx’ta felsefi bir anlama dönüştürdüğünü belirterek, Marx'ın diyalektiğinde yabancılaşma kavramının pratik bir içeriğe kavuştuğu üzerinde durur. Buna göre, üretici olan insan, ürettiği ürüne el koyan güce düşmanlaşmakta ve üretici ürüne yabancılaşmaktadır. Böylece insan kendi etkinliğiyle kendini dışlaştııırken, aynı zamanda, hem ürününe hem de kendine 'yabancılaşmış’ olur. Ancak, aynı zamanda 'yabancılaşma’ Ernst Fischer’e göre, çağdaş bilimin buluşlarıyla ve toplumsal anlaşmadaki geriliğin çe- 
lişmesi olarak da gerçekleşmektedir (Fischer'den aktaran Tunalı, 2009: 65) ${ }^{8}$.

Tunalı (2009: 66), ‘yabancılaşma’yı makale konusu kapsamında ilişkilendirdiği üzere, aşağıdaki gibi açıklamaktadır:

“....insanları yabancılaşmaya götüren sadece bu soyut-rasyonel, matematiksel-bilimsel gerçeklik değildir. Belki de bundan daha çok gündelik yaşamlarını belirleyen teknolojik gelişmeler ve oluşumlardır. Bu yüzden bilimsel- teknolojik gelişme ile tinsel-toplumsal yapı arasında çözülmesi güç çelişkiler ortaya çıkmaktadır. Bilim, teknoloji ve endüstrinin bu denli büyük ölçekte gelişmesine karşılık sosyokültürel yapı, yüzyıllarca insan yaşamını belirlemiş olan bilimsel, etik ve estetik değerler sistemini yitirmiştir. Bu da insanı topluma, toplumsal kurumlara ve yeni değerler sistemine karşı 'yabancılaşma’ya götürmüştür.".

Tunalı'nın yabancılaşma kavramının yanı sıra, James ve Gell'in kültürün-geleneğin kullanımı ile ilgili görüşleri de bu çalışmada önem taşımaktadır. 19. yüzyıl sonunda ve 20. yüzyıl başında, halk kültürüne göndermelerle birlikte, Doğulu sembollerin - Batı dünyasındaki etnik zevkleri tetiklediği için - hediyelik eşyalarda kullanılması önem taşır. Ayrıca, bu dönemde, devasa arkeolojik eserler, ait olduğu topraklardan koparılmış ve yeni yurtlarında sergilenmiştir. James (2013: 125), bunların ancak temsil değerleri olabileceğini belirtir. Buna göre, 'kültür', ait olmadığı bir yerde sadece temsil edilebilmektedir. Ancak, James'in (2013: 125) aktardığına göre Gell, 'sanat antropolojisi' kavramını ortaya sürerek, bunun söylenen ve temsil edilen şeylerle değil, yapılan şeylerle ilgili olduğunu ve analizlerin odağında ‘biyografik zaman'ın, yani insanların yaşadıkları gerçek zaman ve birbirleriyle olan ilişkilerinin varlı̆̆ı olduğunu belirtmektedir. Bu durumda kültür, ait olduğu zamanda ve mekanda özgünlüğünü koruyabilmektedir. Öte yandan Gell, 'temsil değer’e dönüşen geleneksel şekillerin ve desenlerin kendi başlarına bir etki yaratma güçleri olduğuna ve kültürdeki simgesel önemlerine değindikten sonra, bu desenlerin kendi do- ğasında sanat yapmak için üretilmediklerini belirtir. Ona göre bu desen ve şekiller, ait oldukları ortamdaki kişisel ve toplumsal kimliği yok olmaktan korumak için verilen mücadelede ortaya çıkmış çabalardır (Gell'den aktaran James, 2013: 127). James (2013: 185), buna daha net bir biçimde yaklaşarak, bir giysideki geleneksel bir motif, renk ya da geleneksel başka herhangi bir öğenin aslında bir metne ilişkin bir yaklaşım taşıdığını ifade etmektedir. Burada kullanılan dil, aşina olunan kültürün temsilcisi, 'simge'si olan herhangi bir öğe ile görme duyusunu harekete geçirmektedir. Tasarım olan bir giyside kültür öğelerinin kullanımı ile etnografik değeri olan eski giysilerin kendi içindeki değerleri farklıdır. Barhtes de, aslında bu yaklaşımı destekler görüştedir; Barthes'e (2008: 117) göre bu durumda tasarım, yoğrumsal (Plastik) niteliktedir, diğeri ise dilseldir. Barthes'in 'tasarım giysi'deki bu yaklaşımı, biçim-yüzey-renk ve uzamsal bağıntılı olarak yorumlanabilir. Ancak, diğerindeki malzemenin sözcükler olduğunu ve bağıntısının da sözdizimsel olduğunu belirtmeliyiz.

Flügel'in yaklaşımı Barthes'i doğrular niteliktedir. Flügel'e (2008: 129) göre, giysilerin üretim tekniklerinden, motif ve desen özelliklerine, giyim- kuşam davranış biçimlerine kadar her alanda derin bir sembolik anlam dizgesi bulunmaktadır. Flügel'in araştırması simge toplumlarının olduğu kadar, Batı dünyasının 18. yüzyıla kadar olan giyim kuşam alışkanlıklarını da kapsamaktadır.

18. yüzyıldan sonra kapitalist bir olgu olarak gelişen modanın gelişim süreçlerine baktığımızda, modanın yayılımı başka bir gelişmeyle karşımıza çıkmaktadır. Bu gelişme, seçkinlerin eğlencelerinin ve modalarının alt katmanlara süzülmesidir. Modernite ve kentleşme bağlamında, kaynakları çok çeşitli olan popüler kültür, hiç de kolay olmayan bir kavramdır. Bunlar arasında, kuşaklar boyunca seçkinlere ait olmuş olan biçimlerin taklidi, festivallerde yeniden yaratılması ve sokak mizahının oluşumu gibi şeyler bulunur. Halk kültürünün üretim biçimleri, ritüellerin giderek artan bir şekilde müzelerde yer alması, festivallerde el sanatları vb. halk kültürü değerlerine yer verilmesi, hediyelik eşya kültüründe konunun öncelik taşıması gibi gelişmeler bu konudaki tüketimin kendisinde 
bir tür manevi hatta dini tonlar taşıyan bir simgesellik olduğunu düşündürmektedir (James, 2013: 325). James'in Danny Miller'den aktardığı bu gelişme, aslında 'popüler kültür'ün malzemesi olarak, kültürün pazarlanması konusunu gündeme getirmektedir. Kültürlenme süreçlerini tamamlayamamış kitlelere simgelerle seslenmek ve onlarla derin kültürel bağlar kurmak, maneviyat bakımından tatmin edici gelebilir. Burada, sanat ve tasarım adına kaygı duyuluyor olmasından çok, popüler kültür yaklaşımı sezinlenir.

Bu bağlamda, Endüstri Devrimi'nin hemen öncesinde geleneksel yaşam biçimini sürdüren Batılı toplumların kendi modernleşmelerinde, Arts \& Crafts Hareketi ve 'Aesthetic Movement' (Estetik Akım) anlayışı ile moda tasarımına yaklaşımlarında etnografyadan yararlanmaları doğru bir yaklaşım olarak tespit edilmiştir. Glasgow Sanat Okulu'nun yaklaşımının da söz konusu dönem için isabetli olduğunu düşünülmektedir. Tarafımıza göre, bu yeni yaklaşımda, zaman ve mekân bakımından bir alışkanlığın ‘yabancılaşma' kaygısıyla devamlılığı söz konusudur.

Gell'in yukarıda bahsedilen biyografik zaman tanımlamasının, günümüzden yüz altmış dokuz yıl önce kurulan Glasgow Sanat Okulu'nun moda tasarımına getirdiği bu yaklaşım için de geçerli olduğu düşünülebilir. Bu, zamanın ruhuna uygun bir gelişmedir. 'Estetik Akım'ın önerdiği 'giyilebilir sanat' (wearable art), 'sanatsal elbiseler'in başvurduğu geleneksel malzeme, teknik ve kompozisyon özellikleri, geçiş döneminde işlevini yerine getirmiştir.

\section{Modanın Doğal Hali ve Sonuç}

Barthes'e (2008: 119) göre, moda toplumbilimi, başlangıçta hayal edilmiş olan (tasarımcıların tasarladığı) bir modelden hareket eder ve onun, bir dizi gerçek giysi aracılığıyla gerçekleşmesini (modellerin yayılması sorunu) izler ya da izlemek zorundadır. Barthes'in burada bahsettiği, gerçek moda sürecidir ve bu nedenle moda, doğası gereği hep yeni şeyler önermelidir. Göle'nin (2008: 147) Baudrillard'dan aktardığına göre, modanın amacında bitimsizlik vardır. Buna göre, moda sonsuza dek yeni biçimler yaratmak zorundadır. Simmel, Carlyle, Lipovetsky, Barthes ve Baudrillard'ın moda konusunda buluştuğu or- tak nokta, her 'yeni'nin yerine daha yeni bir 'yeni' geçecek, bu yeni ‘yeni’ bir önceki 'yeni'yi eski yapacaktır.

Bu tespitlere göre, günümüzde gelenekçi yaklaşımların, modanın bitimsizlik üzerine kurulu doğal halinin çevresinde gelişen sektörel gerçeklik ile örtüşmediği söylenebilir. Giysi tasarımını içeren modanın üretim-tüketim sarmalında, tekstil hammadde üretiminden, dokuma ve baskı teknolojilerine, iplik, desen, kumaş, form- ürün tasarımının her aşamasına, kumaş üretimi ve kumaştan elde edilen ürün üretimine ve tüm bunların tanıtımı, pazarlanması ve uygulama önerilerine kadar geniş bir alanı kapsayan bir sektör ile karşılaşmaktayız. Bu sektör, belirlenmiş eğilimlerine göre üretim yapmakta ve daima yeni olanın tasarlanması, üretilmesi, tanıtılması, pazara sunulması ile ayakta durmaktadır.

Günümüzde moda sektörünün söz konusu gerçekliğinde kendi modamızı yaratmak düşüncesi kuşkusuz önemlidir. Bu bağlamda tasarımcılar, müzeler ve arşivler gibi değişik kaynaklardan esinlenebilir. Bu esinlenmede kültürün değişken bir olgu olduğu ve çağın kendi gelişim sürecinde çeşitli etkenlere bağlı olarak kendiliğinden başkalaşması hususunun göz önünde bulundurulması önerilmektedir. Aksi takdirde, 'geleneksel' bir giysiden, motiften esinlenilerek/yararlanılarak yapılan bir 'tasarım'ın, yüzeysel bir çalışma olduğu düşüncesi uyanmaktadır. Oysa ki kültürün değişkenliği ile sanat ve tasarım olgularının kendi tarihsel gelişimleri yakın ilişki içindedir. Sanat ve tasarım ait olduğu çağa ait önermelerde bulunur ve bu nedenle çağcıldırlar (Ergür, 1997: 171). Sanatçı-tasarımcı yaşadığı çağın önermelerini gerçekleştirmezse, gelecekte bugünün izleri nasıl sürülebilir?

Yaşadıkları çağa dair önermelerde bulunan sanatçılar/tasarımcılar, gelenekten/kültürden elbette yararlanabilirler. Fakat burada, tekrar gerçek amacın ne olduğunun sorulması gerekmektedir. Moda tasarımında gelenekçi yaklaşımlarda gerçek amaç, bu makalenin başında sorgulanmış olan konuların dışında, 'özgün olmak' mıdır? Eğer amaç 'özgün olmak' ise, buna verilecek birkaç örnekle açıklık getirebiliriz. Söz gelimi, Hüseyin Çağlayan, Issey Miyake, Belçikalı tasarımcılar Martin Margiela, Dries Van 
Noten, Dirk Birkembergs, Walter Van Beirendonck, Dirk van Saene, Ann Demeulemeester kendi özgün modalarını yarattılar (Kipöz, 2014). Çağlayan, antropoloji, mitoloji ve sanat tarihinden beslendi; Miyake, Japon edebiyatından yola çıktı; Belçikalı tasarımcılar ise 'Belçikalı' davranış biçimini idrak ettiren kalıp ve biçimlerle şaşırtıcı önermelerde bulunarak özgünlüklerini ilan ettiler. Buradan da anlaşılacağı üzere, moda tasarımında ‘özgün’ olmak, tasarımcıların yaratıcı düşünceleri, alan ve literatür araştırmaları ile zenginleşmiş bilgi birikimleri ve yoğun atölye çalışmaları sonucunda mümkün olmaktadır.

Endüstri Devrimi ve sonrasında yaşanan gelişmelere karşın, sanat ve tasarıma hala 'gelenekçi' politik retorik ile yaklaşmak ve dünyanın yüz elli yıl gerisinden yanlış yaparak önermelerde bulunmak ise, 'tarihin tekerini geriye döndürmek'i teklif etmektir.

\section{Notlar}

1 Öte yandan, kadının kapitalist toplumda kamusal alanda görünür olması, çalışma yaşamında yer almaya başlamasıyla geleneksel öğretide yer alan cinsel ayrımcılık belirgin biçimde öne çıktı. Kadınların, kendilerine ihtiyaç duyulan yeni dünya düzeninde değişen rolleri ile kabul edilmeleri uzun yıllar aldı (Callen, 1985: 1-6).

21883 yılında Osman Hamdi Bey tarafindan kurulan Sanayi-i Nefis Mektebi'nin Kumaş Desenleri Atölyesi henüz 1938 yılında kurulabilmişti (Şahin, 2010).

3 Osmanlı Batılılaşma döneminin Avrupa'daki karşılı̆̆ı, 'Avrupa'nın modernleşme dönemi' olarak anlamlandırılmıştır.

4 Batı etkisindeki yeni modalar çoğunlukla Arkeoloji müzelerinin içinde yer alan Etnografya bölümlerinde 'geleneksel giysiler' olarak yer aldı. Bu müzelerin çok azında halk kültürünü yansıtan giysiler, sahip olduğu kültür ile birlikte konumlandirildı.

5 Giysilerin müzelerde, Avrupalı insan fiziğindeki vitrin mankenlerinde, somut bir kurgudan uzak sergilenmesi ise başlı başına bir sorundur. İzleyiciyi basitleştirilmiş algıya yönlendiren bu sunumlar ne yazık ki gerçeklikten uzaktır.

6 Konuk (2008: 169), 'etnomaskeleme’yi, Katrin Sieg üzerinden şöyle aktarmaktadır: "Maskeleme "hakiki olmayanın oyunbaz alanı', etnomaskeleme ise öteki etnisitelerin bu yolla bir yandan iktidarı icra ederken bir yandan da bunu gizleyen bir özne tarafından teatral bir şekilde cisimleştirilmesidir." Bu makalenin konusu, etnomaskeleme kavramı açısından da irdelenebilir, ancak burada sadece çağrışım yaptırması bakımından kullanılmıştır. Bir başka çalışmada bu konu, 'oryantalizm' ile ilişkilendirilerek ele alınacaktır.

7 Bu makalede yer verilmiş olan 'yeni moda tasarımlarında kullanılan gelenekçi yaklaşımlar, yeni bir alışkanlık yaratma girişimi olabilir mi?' sorusu, 'habitus' kavramına değinmeyi gerektirmektedir. Varlı-Görk'ün (2013) belirttiğine göre, 'habitus' kavramı Antik Yunan'da 'ethos' olarak kullanılan bir kavramdır ve günümüzde Bourdieu tarafından 'alan kuramı'nda yeniden kullanılmaktadır. "Bourdieu, kendisinden önce habitus kavramının anlamına yakın anlamları içeren kavramları kullanan düşünürlerden-Hegel'in ethos, Husserl'in Habitualität ve Mauss'un hexis kavramları-esinlendiğini, onların da kendisininkine yakın bir teorik niyetle; yani hem eyleyici feda etmeden özne felsefesinden kaçınmak, hem de yapının eyleyici üzerinde ve onun aracılığıyla yarattığı etkileri hesaba katmaktan vazgeçmeden yapı felsefesinden kaçınmak niyetiyle hareket ettiklerini kabul etmektedir." (Bourdieu ve Wacquant'dan aktaran Varlı- Görk, 2013). Yine de, kavrama farklı bir anlam yüklediğini ileri süren Bourdieu, bu nedenle özellikle alışkanlık dememek için habitus kavramını kullandığını vurgulamaktadır. Demez'in (2009: 18) bildirdiğine göre de, 'habitus' tarihin ürünü olduğundan, tarih içinde sürekli yenilendiğinden, sürekli olarak yeni deneyimlerden etkilenmekte olduğundan kapalı değil açık, yani dönüşen yatkınlıklar sistemidir. Yatkınlıklar kalıcıdır ve bugünden yarına değişmezler. Bu nedenle, moda tasarımlarında geleneksel örgelerin kullanılması önerisi ile 'yeni bir habitus' önermesi yapılıyorsa eğer, bu yanlış bir önerme olarak değerlendirilmektedir. Bu bağlamda, bu makalede, 'habitus' yerine, 'alışkanlık'ın yatkınlıkla ilişkili olduğu düşünülmüş ve bu nedenle 'alışkanlık' kavramı kullanılmıştır.

8 Bkz.: Ernst Fischer, Sanatın Gerekliliği, çev. Cevat Çapan, Konuk Yayınları (1974), İstanbul, s. 215.

\section{Kaynakça}

Arthur, Elizabeth F. (1980). "Glasgow School of Art Embroideries, 1894-1920", The Journal of the Decorative Arts Society (4/ 8): $18-25$.

Barthes, Roland (2008). “Moda Dizgesi”, Cogito (55): 117- 129.

Callen, Anthea (1985). "Sexual Division of Labor in the Arts and Crafts Movement”, Woman's Art Journal (5/6): 1- 6

Demez, Gönül (2009). "Sınıfsal ve Bireysel Kimlik Oluşumunda Beden Sorunu: Habitus” (Beden Özel Sayısı), Toplum Bilim Dergisi (18): 17- 25.

Ergür, Atila (1997). “Gelenek Görenek ve İnançların Halk Sanatına Etkisi”, 5. Milletlerarası Türk Halk Kültürü Kongresi Maddi Kültür Seksiyon Bildirileri, Bildiriler Kitabı, Kültür Bakanlığı Yayınları, 171174.

Flügel, J.C. (2008). “Giysi Sembolizmi ve Giysinin Çok Anlamlılı̆̆ı”, Cogito (55): 121- 132

Göle, Münir (2008). “Sarışın Kadının İçi Boş mu?”, Cogito (55): 142150.

James, Wendy (2013). Törensel Hayvan, çev.: Sevda Çalışkan, İstanbul, Türkiye İş Bankası Yay. 
Kipöz, Şölen. (21. 04. 2014). "Kavramsal Moda Tasarımı: Gelişimi, Uygulamaları”, Anadolu Üniversitesi, Mimarlık ve Tasarım Fakültesi, Moda Tasarımı Bölümü Konferanslar Dizisi, Eskiş̧ehir.

Konuk, Kader (2008). "Osmanlı ve Avrupa Arasındaki Karşılıklı Etkileşimde

Etnomaskeleme: Lady Mary Wortley Montagu'nun Rolünü Yeniden Canlandırmak", Cogito (55): 168-191.

Lehnert, Gertrud (2000). A History Of Fashion, Almanya: Könemann.

Os, Nicole Van. (2002). “Milli Kıyafet, Müslüman Osmanlı Kadını ve Kıyafetinin Mahiyeti”,

Türkler (Cilt 14): 142, Yeni Türkiye Yayınları.

Osman Hamdi Bey \& Marie de Launay (Ahmet A. Ersoy'un Önsözü) (1999). 1873 Yılında Türkiye'de Halk Giysileri, Elbise-i Osmaniyye Levant Times\&Shipping Gazette Basımevi'nden tıpkı basım), çev.: Erol Üyepazarcı. İstanbul: Sabancı Üniversitesi Yay.

Stankiewicz, Marry Ann (1992). "From the Aesthetic Movement to the Arts \& Crafts Movement, Studies in Art Education", A journal of Issues and Research (33/3): 165- 173.

Şahin, Yüksel (2006). 1920- 1930 Yılları Arasında Türkiye'de Kadın Siluetinde Moda Anlayışı ve Değişimler, DEÜ- Güzel Sanatlar Enstitüsü Yayınları.

(2010). "Fashion and Textile Design Education in Faculties Giving Art Education in Turkey", 10th World Textile Conference, June 21- 23, 2010, Vilnius- Litvanya (CD ortamında).

(2011/4). “Geleneksel Kadın Giyimi Kesim Tekniğinde Modanın Etkisi”, Folklor Edebiyat Dergisi (68): 181- 185. Tunalı, İsmail (2009). Tasarım Felsefesi, İstanbul: Yem Yayınları.

Varlı-Görk, Reyhan (2013). “Oyun İçin Oynamak” Sözlü Bildiri, 2. Hasan Ünal Nalbantoğlu Sempozyumu, Ankara-ODTÜ: 27-29 Mart 2013. 